\title{
A More Practical Method for Explaining Supply
}

\author{
Yi-Jang $\mathrm{Yu}$ \\ Department of Economics, Ming-Chuan University \\ 5 Der Ming Road, Gui Shan District, Taoyuan County 333, Taiwan, R. O. C. \\ E-mail: yjyu@mail.mcu.edu.tw
}

Received: January 26, 2013

Accepted: February 22, 2013

Online Published: March 7, 2013

doi:10.5430/rwe.v4n1p76

URL: http://dx.doi.org/10.5430/rwe.v4n1p76

\begin{abstract}
To rewrite our economics textbooks, we must begin by describing more realistically what is occurring for a producer. Moreover, when uncertainty or risk is taught, the Markowitz portfolio theory must be referred to for association. This study shows that, by applying both elements of the expected rate of return on investment and portfolio theory, a vast range of supply issues, including several from accounting to management and production to economic development, can all be logically explained.
\end{abstract}

Keywords: Supply, Uncertainty, The expected rate of return on investment, Portfolio theory

\section{Introduction}

In every typical economics textbook, the supply curve is illustrated within a "quantity (Q) - price (P)" plane. However, this type of background is inappropriate for showing any cost information, because the price of a product is determined in the consumption market, but its cost is in the production market. Moreover, the relationship between them is rarely perfect. Prices in the consumption market are usually more rigid than the costs in the production market. Furthermore, even if the discussion can be confined in a world with no uncertainty, to make price and cost to be perfectly correlated would still require the following two strict conditions: no improvement in technology and perfect competition (Hicks, 1983, p. 91). Moreover, with the addition of uncertainty, price and cost can never be perfectly correlated with each other. Therefore, why portfolio theory (thus far, the most standardized tool and framework for analyzing uncertainty) has not been adopted in any economics textbook is perplexing.

Basically, either price or cost information does not reveal the whole story of the producer. This is why profit or the rate of return on investment (ROI) remains thus far the most important figure for every producer. Therefore, when price and cost cannot be presented simultaneously in a simple Q-P plane, a different manner of presenting them in a combined fashion must be considered. This is important because supply and its associated concepts will be clarified only after the incentive of production is properly described.

The introduction of the economics textbook must be reconsidered to provide a more realistic explanation of the supply concept. This study suggests that by applying both elements of the expected rate of ROI and portfolio theory, the new necessary beginning can be provided realistically and can be extended to explain a vast range of supply issues in economics.

\section{Rate of Return on Investment versus Price}

Using a Q-P plane to draw the supply curve indicates that the cost factor is already placed under the assumption of ceteris paribus. Changing the scale from using price to using a dollar sign is futile when both the price and cost of a product cannot be forced to have a perfect relationship, which clearly shows that the analytical background must be redesigned to simultaneously reflect price and cost in the supply curve.

For every producer, only capital spent for production can be regarded as a current actual investment regardless of the amount prepared. The remnants can only be treated as idled capital, which has no marginal product, and therefore, is not a factor of production (Hicks, 1983, p. 123). By assuming that no inventory remains, current returns from investment are current sales, which can be represented as an average price $(P)$ per unit multiplied by the total quantity sold $(Q)$. Accordingly, the one period rate of ROI $(K)$ can be represented as $(P-C) / C$, where $C$ is the average cost per unit. This is evidently the most direct and equitable method for merging price and cost into one 
measure.

For most scenarios, current costs of production (i.e., investment capital) can be predetermined by a producer, but rarely the price of the product. Moreover, controlling both the price and cost for a longer period is impossible. Therefore, uncertainty cannot be disregarded even for a short-term analysis, and the original certain $K$ must be replaced by an uncertain $\widetilde{K}$ that represents $(\widetilde{P}-C) / C$.

A threshold of survival or an opportunity cost $\left(r_{f}\right)$ can exist for every producer. Under the assumption of maximizing the expected rate of ROI, the relationship between $E(\widetilde{K})$ and $Q$ for a particular producer can be presented as Fig. 1, where $Q_{h}$ is the current produced and sold quantity, and $E\left(\widetilde{K}_{h}\right)$ is the current expected rate of ROI. The curve linking $r_{f}$ and $h$ is drawn to reflect both the ability and willingness of the producer, and the marginal diminishing effect on $E(\widetilde{K})$; thus it can be regarded as the possible production line for this producer.

$<$ Insert Figure 1 Here $>$

Although the maximum profits point may be located on the right side of point $h$ along the $r_{f} h$ curve, it is only a possibility. Therefore, the assumption of maximizing the expected rate of ROI rather than expected profits is used in this study for better precision and equity.

\subsection{Industrial Production Line}

The possible production line of one producer (Figure 1) cannot be summed over all producers in the same industry to generate the potential production line for the industry. This is because the industry itself is not a real identity; it may have a collective ability for engaging business, but no actual will. Therefore, drawing the production line of an industry must begin from the quantity provided by the producer/s with the lowest expected rate of ROI $\left(E\left(\widetilde{K}_{L}\right)\right)$, continuously until the producer/s with the highest expected rate of ROI $\left(E\left(\widetilde{K}_{H}\right)\right)$ can be included. Moreover, because a threshold of survival for the whole industry can exist, the extent of an expected impact can be directly analyzed when the threshold approaches above the $E\left(\widetilde{K}_{L}\right)$.

\subsection{Performance Evaluation}

The manner in which to evaluate the performance of $\widetilde{K}$ cannot rely solely on $E(\widetilde{K})$ when uncertainty also matters. As Yu (2012) indicated, a two-dimensional rule of dominance must be applied and it can be represented as WINDEX, the main ingredient of which coincides accidently with the Sharpe ratio.

$<$ Figures $2 \mathrm{a}$ and $2 \mathrm{~b}$ Here $>$

When using $E(\widetilde{K})$ and its related $\sigma$ to define each product, according to portfolio theory, if a set of different products is served by a producer, then the efficient frontier from all products can be represented as $e f_{1}$, as shown in Figs. 2a and 2b. Consequently, the optimal allocation of production resources can be determined as the tangential point intercepted by a line initiated from $r_{f}$ and the efficient frontier $e f_{1}$. For WINDEX, this tangential point would represent the highest possibility of success to perform better than the threshold of survival or opportunity cost $r_{f}$.

As is shown in Figs. 2a and 2b, either directly raising $E(\widetilde{K})$ or reducing $\sigma$ can lead to a better optimal position, and hence, a higher WINDEX. Therefore, for a producer or even a nation, whenever the opportunity of raising $E(\widetilde{K})$ is disappearing, strategies focusing on reducing $\sigma$ can still be considered.

\subsection{Industrial Structure}

Figure 1 shows that the main difference between a monopolist and a producer in perfect competition is that the monopolist acts as a price maker and can generate a better $E\left(\widetilde{K}_{h}\right)$, whereas the producer acts as a price taker and can easily fall into the trap of cost competition. Furthermore, the empirical conclusion about risk diversification provided by Fama (1976) should also be applicable in the real economy. Therefore, if the part of individual risks in an industry can still be significantly reduced by a newcomer, then this industry must be operating under an oligopoly; otherwise, this industry has already assumed a perfect competition. 
Within the $\sigma-E$ analytical background, characteristics of perfect competition can be listed to chiefly include the following: (a) No individual producer can significantly affect the efficient frontier, and hence, the optimal allocation of production resources and the minimum- $\sigma$ portfolio of the industry; (b) a closer present allocation of production resources to the minimum- $\sigma$ portfolio of the industry indicates a higher degree of competition for the whole industry; and (c) if the present allocation of production resources non-significantly deviates from the minimum- $\sigma$ portfolio in the econometric sense, then the whole industry must operate under a condition of perfect competition. The necessary premise is that this minimum- $\sigma$ portfolio can legitimately represent the systematic risk of the industry.

The inclusion of uncertainty can always lead to examining matters differently. According to portfolio theory and its assertion of the optimal allocation of resources, Figures $2 \mathrm{a}$ and $2 \mathrm{~b}$ show that a monopoly is rarely an optimal choice for an industry, and neither is perfect competition. Furthermore, as mentioned, if the conclusion by Fama (1976) is correct, then no single company or state can dominate an entire market.

\section{Connections with Other Academic Fields}

If economics can serve as the foundation for other academic fields, then it must be capable of providing clear and direct connections between them. For this study, this task can be accomplished by directly applying both the expected rate of ROI $\widetilde{K}$ and portfolio theory.

First, $\widetilde{K}$ can be presented with more details in accounting. The main concern is, therefore, how changes in one particular accounting number can affect $E(\widetilde{K})$ and its related $\sigma$, and hence, the business activities of a producer. Next, various management issues can already be discussed directly with respect to $\widetilde{K}$ and its related $\sigma$. For example, based on the goal of maximizing $E(\widetilde{K})$, a $\$ 1$ cost reduction is clearly more efficient than a $\$ 1$ price increase when other factors are equal. Even if the producer rewards every $\$ 1$ cost reduction back to his or her customers by cutting the price by the same amount, $E(\widetilde{K})$ can consequently still be raised. When Wal Mart declares that it represents its customers when cutting the costs of their products, it certainly also works for better rates of ROI. However, this intention can only be fulfilled by continuous expansions of their total sales, and hence, the number of stores.

Once a producer is confronted with the pressure of competition, which means gradually losing control over devising pricing schemes, cost reduction will eventually become necessary. Obviously, a greater cost reduction that can be attained indicates a more fragile producer for facing a serious cost increase (in percentage) in the future. This may serve as the major part of unsystematic forces that can cause the business cycle of a producer or an industry under competition. Solving this problem requires innovation, and the goal is to regain the ability to form pricing schemes. After the advantages of globalization can be sufficiently materialized, only producers equipped with greater innovation abilities can have better control for devising product prices.

According to portfolio theory, a local store and a Wal Mart chain are not operating on the same or a similar level of systematic risk; hence, they do not have equal grounds to compete with each other. This is why the acceptance of a Wal Mart or alike must be evaluated with care, especially when small local stores are tied to local relationships and do not ship away their generated incomes. Although Wal Mart can save people certain expenditures, these savings are created by sacrificing important local relationships and incomes.

If a producer intends to expand more lines of products, then a performance evaluation must rely on portfolio theory. As shown in Figures $2 \mathrm{a}$ and $2 \mathrm{~b}$, unless a new product or a set of new products can improve the position of the efficient frontier within a selected time, no expansion should be considered. Moreover, the performance of individual product can also be objectively evaluated in a similar manner. When the optimal allocation of production resources can represent the opportunity of development that is allowed by the environment, its deviation from where one product is positioned can thus be used to evaluate the performance of this product. If the trend of this deviation is rising, this certainly means that the product is not performing well even if its $E(\widetilde{K})$ can increase. Conversely, a fall in $E(\widetilde{K})$ may not indicate poor performance when the WINDEX of the optimal allocation of production resources would deteriorate even further. 
Third, to reduce the uncertainty in $\widetilde{P}$ and $\widetilde{K}$, or even $\widetilde{C}$ if more than one period of production is planned, certain contracts of order in advance or hedging tools must be arranged through the financial market. When the producer needs to finance his or her investment capital partially or completely, the association from the finance market is unavoidable. The switch from debt financing to equity financing for companies can also be deemed a natural consequence of performing the inevitable act of having to cut costs. German companies have a worldly competitive advantage in innovation, and this may explain why debt financing is still functioning relatively well in Germany.

Finally, whenever sectors other than the economic sector are concerned, a new identity including the national economy portfolio as a member must be created to pursue continuous national development. Even the external costs of production have no choice but to internalize by doing so. Doubt might arise accordingly, such that external costs or benefits can hardly be measured with precision. However, this should not become a serious concern to deter the creation of a higher-level portfolio over one of the national economy. This is because, according to marginal analysis in economics, marginal changes but not what to start are more important for analyses.

By following portfolio theory, the first goal of pursuing continuous national development and the second goal of maximizing the expected rate of ROI for a producer can be directly combined; that is, to device a schedule to gradually provide more variety and quantities of new products that can better meet the first goal. Accordingly, the new optimal allocation of production resources can be devised by introducing these new constraints into the original maximization solution. Other than a social or religious approach to accomplish the first goal, this may be termed the economic approach to create a better future.

\section{Development Issues}

The developmental strategy of a company in either an expansion or a recession stage can be different. As shown in Figure 2a, expansion means that a company can still have numerous opportunities to introduce new products or open new markets to raise its expected rates of ROI. A recession means the opposite, and the company should look for opportunities to reduce its systematic risk. Strategies that can be considered accordingly can include mergers or acquisitions, or even globalization.

Similar discussions are also applicable to industry identities. However, because the scale of an industry must be larger than that of its individual producers, more potential strategies can be available for the industry. For example, if an industry is heading for a recession, the strategy of creating new sub-industries can be considered to deepen its structure and degree of specialization.

The analytical framework provided by portfolio theory must also be applicable for nation identities. Taking a regional economic cooperation from two nations as an example, once all different industries listed in either nation can be pooled to solve the optimal allocation of production resources for the combined identity, the outcome should reveal what industry or industries in either nation can dominate in the near future. Furthermore, because identical or similar industries from both nations can also be paired to draw its own efficient frontier and work out its own efficient allocation of production resources, whichever has the better competitive advantage can be determined by examining the trend of those efficient allocation data. Based on the marginally diminishing effect of risk diversification observed by Fama (1976), the number of participants in a regional economic cooperation is better limited to a certain level.

Regarding the efficient frontier in Figures 2a and 2b, with the optimal allocation of resources, the market portfolio in the financial market represents the best opportunity to achieve a predetermined goal or an opportunity cost, and it can certainly serve as the basis to forecast the business cycle of the identity being studied. The business cycle to be expected must reflect the best opportunity that can be allowed by the environment, and how perfect this opportunity can be accomplished is another issue. The time-series WINDEX of the optimal allocation of resources can always have an abstracted trend, with regularity especially within the current cycle that can be directly used to forecast its expected movement. This is a purely technical approach to forecast the business cycle, which is also a unique property that can be provided by WINDEX.

Generally, according to portfolio theory, the government is good at providing systematic management. It should thus encourage the horizontal expansion of the national economy by introducing new industries at expansion stage, and to promote vertical deepening within main industries during recessions. Moreover, governmental intervention can still be considered to draw first a new efficient frontier that can link directly the present situation and the optimal 
allocation of resources at that time, and then exert efforts of adjustment only within the section of absolute advantage in this new efficient frontier; that is, effort that can simultaneously contribute to higher rates of ROI and lower risks. Going beyond that and moving into the next section of relative advantage in the same efficient frontier is unnecessary, where better rates of ROI can still be generated, but with higher risks, unless it is an urgent matter.

\section{Wage Issues}

The combination of $(\widetilde{P}-C) / C$ and portfolio theory can also be applied to explain wage issues. According to portfolio theory, wages can be roughly classified into two categories: Type I with systematic attributes and contributions, and Type II with unsystematic attributes and contributions. Type II wages directly link the inputs of production; that is, the whole process of production cannot be completed without them, and most of their amounts are usually determined before production begins. For Type I wages, their contributions can only be evidenced after products are sold and profits are calculated. Therefore, this linkage with uncertain $\widetilde{P}$ should make their determinations totally different from that of Type II wages, which link to the $\operatorname{cost} C$.

Accordingly, management-oriented (Type I) wages are better contracted annually or on an even shorter term, because they are inadequate if they cannot contribute what they promise. Furthermore, this type of Type I wages, which includes bonuses especially, is better not paid up front, and the performance of wage earners must be evaluated with care. For example, if the cause of bad performance is subjected to systematic effects, then responsibility can most likely be excused. Finally, Type I wages may be appraised by applying an equity pricing system, which can be a similar product of the asset pricing system proposed by $\mathrm{Yu}(2012)$.

Under the viewpoint of portfolio theory, wages represent that provided physically or mentally, and also what has been sacrificed temporarily but significantly in employees' social lives. Personal connections are important assets for pursuing continuous national development. Therefore, sacrifices must be deemed important opportunity costs for both employees and society.

\section{Linking the Demand Side}

Either the supply or the demand curve has unique attributes, and communicating with each other can only be achieved through a common language. According to portfolio theory, this common language can include a set of systematic and unsystematic variables capable of explaining major and minor effects on both the supply and demand of a certain product. After inspecting the rate of ROI measure $(\widetilde{P}-C) / C$, the endogenous factor can only be $\widetilde{P}$, and the exogenous factors must work through both $\widetilde{P}$ and $C$. By definition, $\widetilde{P}$ can also be deemed an unsystematic factor if it can be controlled by the producer. Conversely, exogenous factors must be treated as systematic ones that cannot be under the control of the producer. Accordingly, for supply, the common language to communicate with demand can only be the price as the sole unsystematic factor, in addition to a set of important systematic factors that can also significantly affect demand.

\section{Conclusion}

This study was not conducted as a criticism to previous research, which is the foundation of our knowledge. It is merely a suggestion in the hope of inviting more helps to make our economics textbooks capable of explaining and even solving current global economic problems.

If we were to rewrite our economics textbooks, we must obviously start describing more realistically the ordeals a producer faces. Producers can always have different incentives behind their investments, but maximizing expected profits or the expected rate of ROI should be the most common one. Once uncertainty or even risk also requires consideration, portfolio theory must be used for association. As shown in this study, by applying both elements of the expected rate of ROI and portfolio theory, a wide range of supply issues, from accounting to management and from production to economic development, can all be logically explained. Hopefully, a better opportunity to rebuild economics, the fundamental science for other academic fields, can be achieved.

Suggestions from this study are only applicable to non-financial products. In economics, forces influencing prices can always be presented as a function of supply and demand or of microeconomics and macroeconomics. Financial products are highly homogeneous because they use money to earn money. Therefore, the general function of supply and demand would be too subjective to be suitable for pricing them. The other alternative of applying a function of microeconomic and macroeconomic factors is also facing serious difficulty in quantifying the necessary 
environmental variable for their pricing. Accordingly, a function of systematic and unsystematic variables is the best choice (Yu, 2012). Moreover, when pricing a new financial derivative such as a new option is concerned, the law of no arbitrage, instead of the principle of supply and demand must be applied (Yu, 2013).

Economics is still dismal, but it can be filled with forces of innovation. As economists, we must work hard because completing an adequate economics textbook that suffices to address the issues of the present still requires more time.

\section{References}

Fama, F. F. (1976). Foundations of Finance. New York, NY: Basic.

Hicks, J. (1983). Classics and Moderns: Collected Essays on Economic Theory Volume III. Oxford, England: Basil Blackwell.

Yu, Y. (2012). The Asset Pricing System. Modern Economy, 3(5), 473-480.

Yu, Y. (2013). Option pricing with economic feasibility. Modern Economy, 4(1), 73-76.

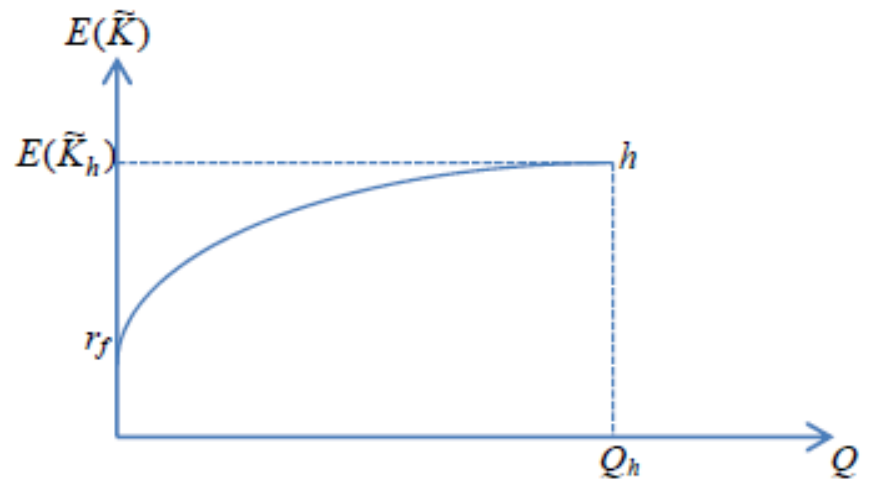

Figure 1. The relationship between $E(\widetilde{K})$ and $Q$

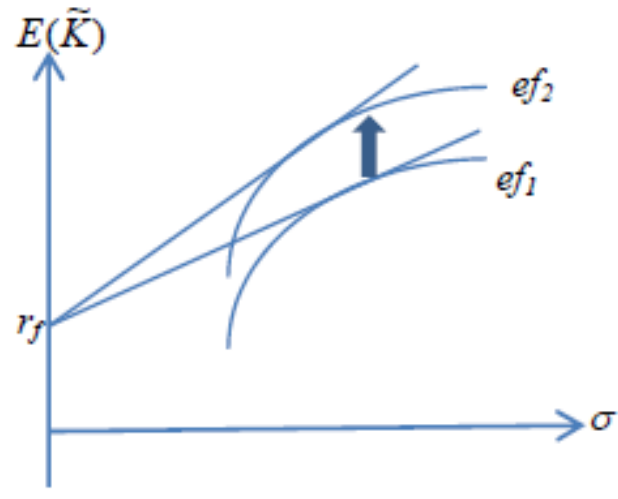

Figure 2a. An upward shift of $e f_{1}$

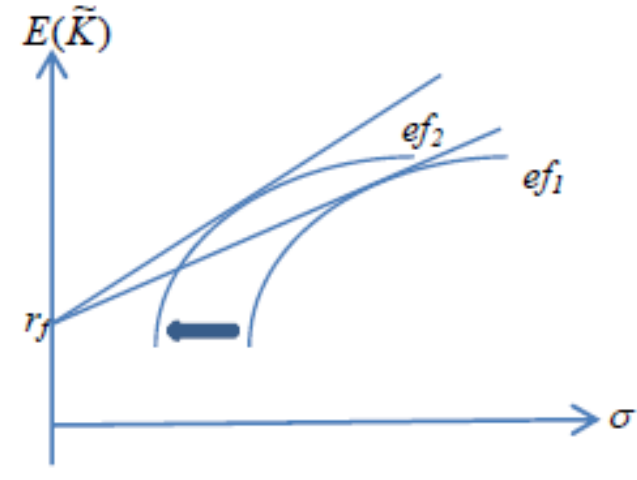

Figure 2b. A leftward shift of $e f_{1}$ 